\title{
MORBIDITIES ASSOCIATED WITH INCREASED BMI IN PREGNANT WOMEN.
}

1. MBBS, FCPS

Assistant Professor

Obstetrics and Gynaecology

Isra University Hyderabad.

Correspondence Address: Dr. Sarwat Memon

Obstetrics and Gynaecology Isra University Hyderabad.

dr.sarwat memon@hotmail.com

Article received on:

22/09/2018

Accepted for publication:

07/02/2019

Received after proof reading: $31 / 07 / 2019$

\begin{abstract}
Sarwat Memon ${ }^{1}$
ABSTRACT... Obesity is the major threat to social and medical wellbeing in Pakistan and worldwide. Increased BMI poses certain risks to mother as well as fetus. The objective of this study is to assess the maternal and fetal morbidities in women presenting with increased BMI during pregnancy. Study Design: Descriptive cross sectional study. Setting: Isra University Hospital. Period: $1^{\text {st }}$ June 2017 till Nov 2017. Materials and Methods: 100 Patients with singleton pregnancy were included in this study. Results: Total 100 female patients were taken in this study and it was observed that $67 \%$ of them were in age limit between $21-30,27 \%$ were above 31 yrs old and only 6\% were found to be below 20 yrs. Amongst them 34\% were diabetics, 29\% hypertensive, $10 \%$ had UTI, $7 \%$ were suffering from asthma and remaining $10 \%$ had multiple problems. Conclusion: It was concluded that there are complex and noteworthy socio- statistic imbalances related to different age groups, parity status and BMI. It was also concluded that increased no of patients are at high risks of maternal and fetal complication rates and require proper access to antenatal care. Facilities and interventions should be provided to improve both maternal and fetal health care and reduce the risks of adverse effects of increased BMI.
\end{abstract}

Key words: Birth Outcomes, BMI, Diabetes, Fetal Health, Maternal Health, Obesity

Article Citation: Memon S. Morbidities associated with increased BMI in pregnant women. Professional Med J 2019; 26(8):1345-1347

DOI: $10.29309 / T P M J / 2019.26 .08 .3881$

\section{INTRODUCTION}

Obesity has been the universal focus for today's world since past 25 years and expected to remain so for predictable future for developed and underdeveloped countries. ${ }^{1,2} \mathrm{~A}$ huge list of factors like sedentary lifestyles, dependence on technologies, over consumption of high calorie low quality fats, alcohol, diminished physical activity, environmental influences have found to be contributory to obesity by creating dysregulation in body metabolism. ${ }^{3}$ It is usually depicted utilizing the body mass index (BMI = kg BW/ height in $\mathrm{m} 2$ ). WHO discern between overweight (BMl $25-30 \mathrm{~kg} / \mathrm{m} 2)$, obesity (BMI $>30 \mathrm{~kg} / \mathrm{m} 2)$ and extreme obesity as $(B M I>40 \mathrm{~kg} / \mathrm{m} 2)^{2}$.

Maternal weight is presently viewed as a standout amongst the most normally happening hazard factors seen in obstetric practice. Obese women have shown increased chances of complications like miscarriages, gestational diabetes, preeclampsia, venous thromboembolism, induced labour, caesarean section, anaesthetic complications and wound infections, breastfeeding in contrast to healthy pre pregnancy weighted. Not only that, but childrens born to obese patients have also shown increased possibilities of stillbirth, congenital anomalies, prematurity, macrosomia and neonatal death.

In United States alone more than one third of the women are found to be obese ${ }^{5}$, uk showed rapid increase from $9 \%$ to $16 \%$ and in Netherlands up to $42 \%$ incline in obesity rate. ${ }^{6}$

Considering the facts that people are consuming more and moving less throughout the world along with rapid rise in complications both maternal and fetal, this study was felt to be of deemed importance to assess the maternal and fetal morbidities associated with increased BMI during pregnancy. 


\section{METHODOLOGY}

This study was conducted at Isra University Hospital during time period of $1^{\text {st }}$ June 2017 till Nov 2017. 100 Patients with singleton pregnancy were included in this study.

\section{RESULTS}

Total 100 female patients were taken in this study and it was observed that $67 \%$ of them were in age limit between 21-30, 27\% were above 31 yrs old and only $6 \%$ were found to be below $20 \mathrm{yrs}$ (Table-I). Amongst them 34\% were diabetics, 29\% hypertensive, $10 \%$ had UTI, $7 \%$ were suffering from asthma and remaining $10 \%$ had multiple problems (Figure-1). Fetal complications were absent in about $63 \%$ of patients while $15 \%$ has macrostomia, 14\% low birth weight, 6\% IUGR and $2 \%$ suffered from congenital abnormalities (Figure-2). 30\% were primary gravida, 24\% had NVD, $6 \%$ had both NVD and C- section while $40 \%$ had section (Figure-3).

\begin{tabular}{|c|c|c|c|c|}
\hline \multirow{2}{*}{$\begin{array}{l}\text { Age } \\
\text { N (\%) }\end{array}$} & $\begin{array}{l}\text { Below } \\
20 \text { Yrs }\end{array}$ & $\begin{array}{c}21-30 \\
\text { Yrs }\end{array}$ & $\begin{array}{l}\text { Above } \\
31 \text { Yrs }\end{array}$ & Total \\
\hline & 06 (6\%) & $\begin{array}{c}67 \\
(67 \%)\end{array}$ & 27 (27\%) & $\begin{array}{c}100 \\
(100 \%)\end{array}$ \\
\hline \multirow{2}{*}{ Trimester } & $1^{\text {ST }}$ & $2^{\mathrm{ND}}$ & $3^{\mathrm{RD}}$ & \\
\hline & 19 & 38 & 43 & 100 \\
\hline \multirow[t]{2}{*}{ BMI } & $\begin{array}{l}\text { Normal } \\
(18-25)\end{array}$ & $\begin{array}{l}\text { Over } \\
\text { weight } \\
(>25)\end{array}$ & $\begin{array}{l}\text { Obese } \\
(>30)\end{array}$ & V.Obese \\
\hline & 34 & 45 & 17 & 4 \\
\hline \multirow{2}{*}{$\begin{array}{l}\text { Parity } \\
\text { Status }\end{array}$} & $\begin{array}{l}\text { PRIMI } \\
\text { Gravida }\end{array}$ & $2^{\mathrm{ND}}$ & 3 or $>$ & \\
\hline & 30 & 28 & 42 & 100 \\
\hline
\end{tabular}

Table-I. Socio-demographic data of included population

Maternal Morbidities

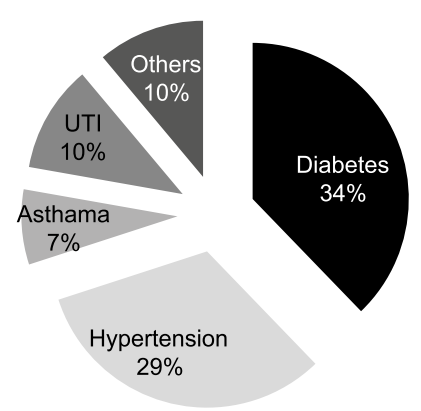

Figure-1.

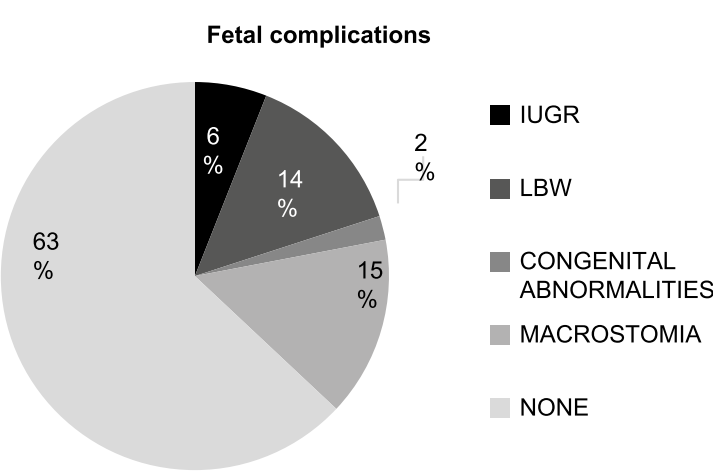

Figure-2

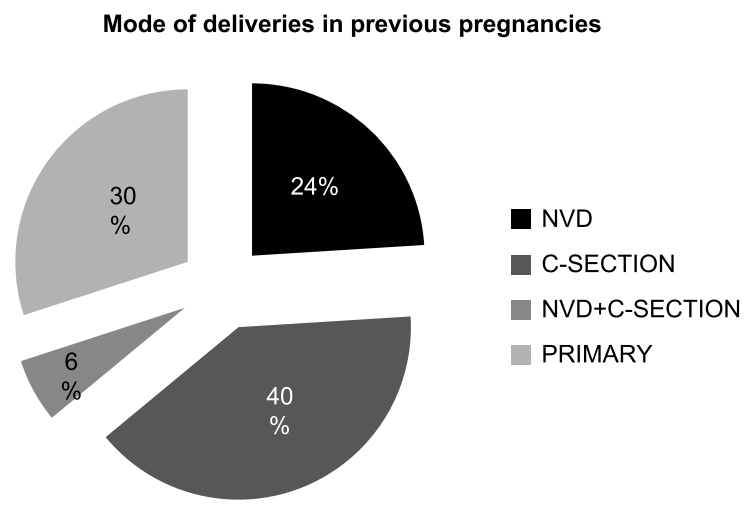

Figure-3.

\section{DISCUSSION}

In our study out of 100 patients, $67 \%$ fall into age limit of 21-30 yrs while $27 \%$ were above 30 yrs old. $6 \%$ were also found to be below $20 \mathrm{yrs}$ of age. 19 patients were in their first trimester, 38 in $2^{\text {nd }}$ while 43 in their $3^{\text {rd }}$ trimester. According to $\mathrm{BMI} 5$ pt were underweight, 32 had normal BMI, 45 overweight, 17 obese whereas 4 were very obese. Analyzing parity status in our study, it was found that 30 were primi gravid, 28 has their second pregnancy while 42 pt had $3^{\text {rd }}$ or more. Comparing with another study out of 100 patients 68 of non-obese pregnant and 60 of obese pregnant women were of 20 - 25years group, 24 of non-obese women and 12 of obese women were of 26 - 30 years group, 8 of nonobese pregnant and 28 of obese pregnant group women were of 31 - 35 years group. ${ }^{7}$ Another study found their BMI status according to $1^{\text {st }}, 2^{\text {nd }}$, and $3^{\text {rd }}$ trimester to be $56.9 \%$ \& $55.4 \%$ normal BMI (1\& 2 trimester), 25.4\%,27.1\% \& $31.8 \%$ over weight, $14.3 \%, 14.6 \% \& 18.2 \%$ obese. 
Similarly the same study found parity status $36.4 \%, 34.2 \% \% 32.6 \%$ having their first pregnancy with $\%$ ages in $1^{\text {st }}, 2^{\text {nd }}$ and $3^{\text {rd }}$ trimesters. 2 parity had $16.7 \%, 17.5 \%, 15.1 \%$ while $3+$ parity having $10.4 \% 13.2 \% 12.1 \%{ }^{11}$

In our study it was found that $34 \%$ of pregnant patients had gestational diabetes, $29 \%$ had hypertension, $7 \%$ suffered from Asthma, 10\% from UTI while $10 \%$ had other maternal morbidities. Comparing these results with another study, GDM was found in $6.9 \%$ and hypertension in $8.0 \%{ }^{8}$ of patients where as another study found GDM in $1.3 \%, 6.2 \%$ hypertension and $3 \%$ had asthma. ${ }^{9}$

In our study it was concluded that $15 \%$ of patients had IUGR babies, 14\% LBW, $6 \%$ had macrostomia, $2 \%$ had other congenital abnormalities while $63 \%$ had none of the fetal complications. Comparing these results with other studies, reported $1.9 \%$ macrostomia, $0.3 \%$ IUGR $^{8}$ another study found macrostomia in $11.7 \%{ }^{9}$ whereas still another study reported IUGR ratio to be in $20 \%$ of patients. ${ }^{10}$

Again comparing our results for mode of deliveries in previous pregnancies with other study, we found that $24 \%$ had NVD, $40 \%$ had c- section, $6 \%$ had both mode of deliveries NVD and c- section while $30 \%$ were primaries where as other study shows that $47.9 \%$ had NVD, $20 \%$ had elective C-section and $23.9 \%$ had emergency c-sections. ${ }^{10}$

\section{CONCLUSION}

It was concluded that there are complex and noteworthy socio- statistic imbalances related to different age groups, parity status and BMI. It was also concluded that increased no of patients are at high risks of maternal and fetal complication rates and require proper access to antenatal care. Facilities and interventions should be provided to improve both maternal and fetal health care and reduce the risks of adverse effects of increased BMI.

\section{Copyright(C) 07 Feb, 2019.}

\section{REFERENCES}

1. Stuber TN, Kunzel EC, Zollner U, Rehn M, Wockel A, Honig A. Prevalence and associated risk factors for obesity during pregnancy over time. Geburtshilfe und Frauenheilkunde. 2015; 75(9):923-28.

2. Ogden C L, Carroll M D, Kit B K. et al. Prevalence of obesity among adults: United States. NCHS Data Brief. 2013; 130:1-8.

3. Leddy MA, Power ML, Schulkin J. The impact of maternal obesity on maternal and fetal health. Reviews in Obstetrics \& Gynecology. 2008; 1(4):71-8.

4. Fitzsimons $\mathrm{KJ}$, Modder $\mathrm{J}$, Greer IA. Obesity in pregnancy: Risks and management. Obstet Med. 2009, Jun; 2(2):52-62.

5. Hedley AA, Ogden CL, Johnson CL, Carroll MD, Curtin LR et al. (2004) Prevalence of overweight and obesity among US children, adolescents, and adults. JAMA.1999-2002; 291:2847-50.

6. Schokker DF, Visscher TLS, Nooyens ACJ, Van Baak MA, Seidell JC. Prevalence of overweight and obesity in the Netherlands. Obes Rev. 2007; 8:101-7.

7. Sujatha VV, Sharma KVLN, Rajesh K. High body mass index in pregnancy, its effects on maternal and fetal outcome. Am J Obstet Gynaecol. 2012; 1(1):15-8.

8. Riley L, Wertz M, Mc Dowell I. Obesity in pregnancy: Risks and management. Am Fam Physician. 2018; 97(9):559-61.

9. Castano IB, Sanchez PH, Perez NA, Salvador JJG, Quesada AG, Hernandez JAG, Majem LS. Maternal obesity in early pregnancy and risks of adverse outcomes. PLOS One. 2013; 8(12).

10. Denison FC, Norwood P, Bhattacharya S, Duffy A, Mahmood T, Morris C, Raja EA, Norman JE, LEE AJ, Scotland J. Association between body mass index during pregnancy, short term morbidity and increased health service costs: A population based study. BJOG. 2014; 121(1):72-82.

11. Barber C, Rankin J, Heslehurst N. Maternal body mass index and access to antenatal care: $A$ retrospective analysis of 619,502 births in England. BioMed Central. $2017 ; 17: 290$.

\section{AUTHORSHIP AND CONTRIBUTION DECLARATION}

\begin{tabular}{c|l|l|l} 
Sr. \# & Author-s Full Name & \multicolumn{1}{|c|}{ Contribution to the paper } & Author=s Signature \\
\hline 1 & Sarwat Memon & $\begin{array}{l}\text { Conceived data, data collection, Analysis, } \\
\text { Data input, Editing wrote article. }\end{array}$
\end{tabular}

